\title{
Relative Advance of Eye Movement to the Target in the Rightward Tracking in Schizophrenics
}

\author{
Yoshiniko Matsue and Teruo Okuma \\ Department of Neuropsychiatry, Tohoku University School \\ of Medicine, Sendai 980
}

\begin{abstract}
Matsue, Y. and Oкuma, T. Relative Advance of Eye Movement to the Target in the Rightward Tracking in Schizophrenics. Tohoku J. exp. Med., 1984, 143 (3), 345-349 — Time relationship between the horizontal smooth pursuit eye movement (SPEM) and tracking target in the leftward or rightward tracking was investigated in 28 normal and 25 chronic schizophrenic subjects. Normal subjects were more liable to show a relative advance of SPEM in relation to the target in the leftward pursuit than in the rightward pursuit. These findings suggest that the spatial task such as SPEM depends more on the right hemispheric function in normal subjects. On the other hand, many of schizophrenic subjects showed a relative advance of SPEM to the target in the rightward pursuit. These findings suggest the dominance of the left hemispheric function in eye tracking tasks in schizophrenic subjects. The finding in the present study would support the hypothesis of the left hemispheric overactivation in the schizophrenic patients. schizophrenia; smooth pursuit eye movement; hemispheric laterality ; left hemispheric overactivation in schizophrenia
\end{abstract}

It has been well known that schizophrenics have disorders of smooth pursuit eye movements (SPEM) as reported by Holzman et al. (1973). Although the cause of SPEM disorders in schizophrenics is not elucidated yet, attentional deficit has been hypothesized as one of the causes of the SPEM disorders.

The authors (Matsue et al. 1981; Matsue and Okuma 1981) also confirmed the SPEM disorders in schizophrenics and reported that chronic schizophrenics frequently showed phase delay of the eye movement from the target, particularly when smoothly-moving flicking light spot was used as a tracking target.

In the present study, the authors observed time relationship between the SPEM and the tracking target in detail, and tried to investigate whether there is any difference, or asymmetry, in the time relationship when the eyes tracked rightward or leftward in both schizophrenic and normal subject groups.

Subjects and Methods

Subject

The subjects were classified into two groups. Normal subject group consisted of 20

Received for publication, November 17, 1983. 
males and 8 females of 20-60 years of age (mean age 35.2 years). Chronic schizophrenic group consisted of 14 males and 11 females with the age of 26-46 years (mean age 36.8 years). All subjects were right handed. All of the schizophrenic patients were diagnosed as schizophrenic disorders according to the criteria of DSM-III. The chronic schizophrenic patients had been hospitalized for more than five years, and were taking antipsychotic drugs at the time of the examination. None of the normal control subjects had a past history of psychiatric treatment or any psychopathology at the time of interview.

\section{Procedure}

As a tracking target, a white light spot on a screen of a cathode ray oscilloscope without after-glowing was used. The screen of the oscilloscope was placed $28 \mathrm{~cm}$ apart from the subject in a lighted room. The velocity of the horizontal movement of the light spot varied sinusoidally. The period of the oscillation was two seconds and the width of horizontal excursion was $10 \mathrm{~cm}$ on the screen or in a range of $20^{\circ}$ of visual angle. While tracking the light spot, the head of the subject was held on a chin rest.

Disc electrodes of $10 \mathrm{~mm}$ in diameter were attached on the outer canthi of both eyes, and midforehead ground electrode was also applied. The horizontal electrooculogram (EOG) and a sinusoidal curve representing movement of the target were recorded simultaneously by an ink-writing polygraph and also by a magnetic tape-recorder with a time constant of 1.5 sec. One tracking trail lasted for 60 sec (i.e. 30 cycles of target movement).

Analysis of the data

EOG data showing a relatively regular wave form without drifts were selected by visual observation, and analyzed. The tape-recorded curve representing the movement of the
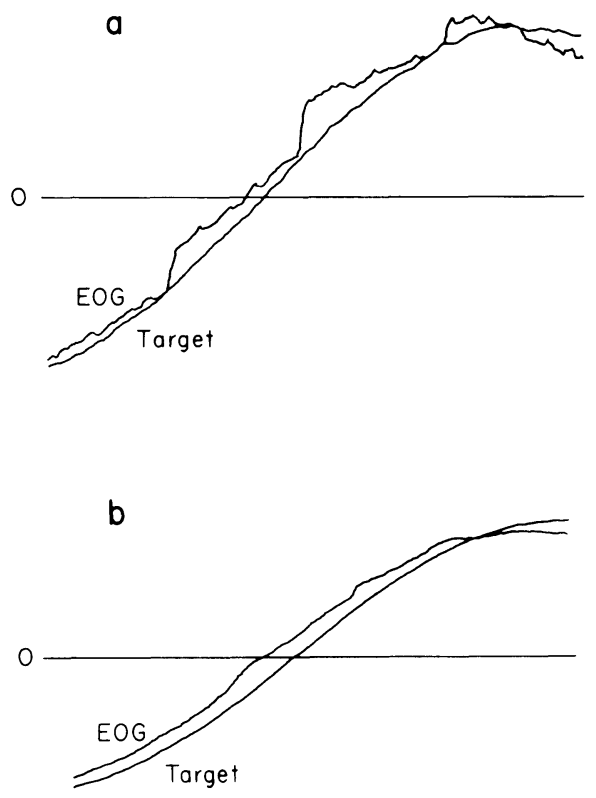

Fig. 1. Measurement of time relationship between EOG and target.

a : An example of original wave form of EOG and target crossed in zero line.

$\mathrm{b}$ : Averaged and smoothened waves of EOG and target (addition $25 \times$ ).

Advance or delay of EOG to the target was measured when the curves crossed the zero line. 
target and EOG were processed simultaneously using a computerized automatic analyzing system (Signal Processor 7T08, NEC-Sanei Instruments, Ltd., Tokyo). The two imput channels, one for target and the other for EOG, were centered and the leftward and rightward movements of the target and eyes (the downward and upward portions of the sinusoidal curves) were added separately for twenty-five times for the purpose of averaging and smoothing with the Signal Processor (Fig. 1). Analysis time was 1,024 msec, and sampling duration was $1 \mathrm{msec}$. The time relationship between the target and the EOG record was measured when the curves crossed the zero line. Data during the initial $10 \mathrm{sec}$ were omitted and those of the succeeding 50 sec (i.e. 25 cycles) were analyzed.

\section{RESUlTS}

Although many of the chronic schizophrenic subjects showed saccadic eye movements superimposed on the smooth pursuit eye movements, it was possible, in all of the examined cases, to measure the time relation between the target and the EOG, because saccadic components were averaged and smoothened.

The time relationship between the target and the EOG was variable. In one case, EOG showed time advance or time delay to the target in both of the leftward and rightward pursuits. In the other case, EOG showed phase advance to the target in leftward pursuit and time delay in the rightward pursuit. In the present study, however, the relative degree of time advance of the EOG in relation to the target, or the difference between the time lag of EOG and the target between the leftward and rightward pursuits was measured and evaluated. For example,
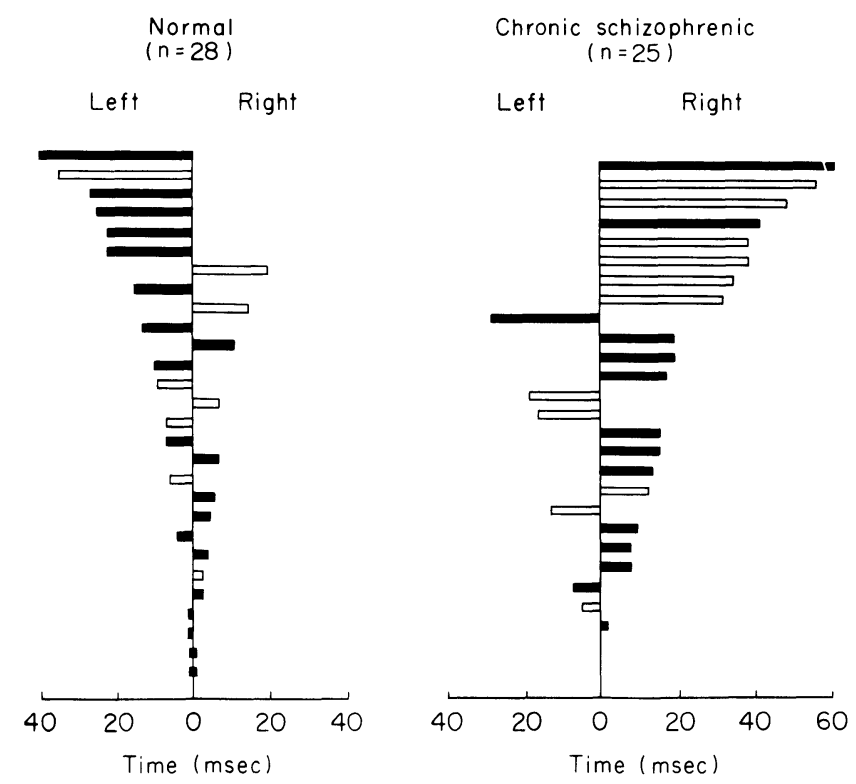

Fig. 2. The directions and extent of relative advance of EOG to the target in normal and chronic schizophrenic subjects. Note that most of the schizophrenic subject showed relative advance in the rightward pursuit.

$\square$ male; $\square$ female. 
TABLE 1. Number of cases showing relative advance in leftward or to the target in normal and schizophrenic groups

\begin{tabular}{|c|c|c|c|}
\hline & & \multicolumn{2}{|c|}{$\begin{array}{l}\text { Number of cases showing } \\
\text { relative advance }\end{array}$} \\
\hline & & Leftward & Rightward \\
\hline A. & Normal controls $(n=28)$ & $16(57.1 \%)$ & $10(35.7 \%)$ \\
\hline \multirow[t]{2}{*}{ B. } & Schizophrenics $(n=25)$ & $6(24.0)$ & $19(76.0) \ddagger$ \\
\hline & $\begin{array}{l}\text { Statistical } \\
\text { significance }\end{array}$ & $\mathrm{A}>\mathrm{B}^{*}$ & $\mathrm{~A}<\mathrm{B} \dagger$ \\
\hline
\end{tabular}

when one subject showed 5 msec advance of EOG to the target in the leftward pursuit and $2 \mathrm{msec}$ advance in the rightward pursuit, the case was assessed as showing 3 msec relative advance in the leftward pursuit. If another case showed $2 \mathrm{msec}$ advance in the leftward pursuit and $2 \mathrm{msec}$ delay in the rightward pursuit, the case was assessed as showing 4 msec relative advance in the leftward pursuit.

Fig. 2 showed left-right direction and extent of the relative advance of EOG to the target in normal and chronic schizophrenic subjects. Among 28 normal control subjects, 16 showed a relative advance in the leftward pursuit, whereas the remaining 10 showed relative advance in the rightward pursuit. Although more than a half of normal control subjects showed a relative advance in the leftward pursuit, no statistically significant was found in the number of cases nor in the mean length of the time of relative advance between the leftward and rightward pursuits in the normal subject group (Table 1). On the other hand, the relative advance in the rightward pursuit was found in 19 of 25 chronic schizophrenic patients and that in the leftward pursuit in only 6 cases, and the difference was statistically significant $(\mathrm{p}<0.001)$. When the direction of the eye tracking with a relative advance was compared between normal and schizophrenic groups, the number of cases showing a relative advance in the leftward pursuit was significantly larger in the normal group than in the schizophrenic group, whereas the number of those showing a relative advance in rightward pursuit was significantly larger in the shizophrenic group than in the normal subject group. The mean length of the time of relative advance in rightward pursuit was significantly longer in the schizophrenic group than in the normal subject group (Table 1).

\section{Discussion}

It was demonstrated in the present study that normal subjects had a tendency to show more time advance of EOG in relation to the target in the leftward pursuit than in the rightward pursuit. If it is assumed that the time advance of EOG to the target in the rightward pursuit means more activation of the left hemisphere than the right, these findings suggest that the spatial task such as the eye-tracking 
rightward pursuits and mean time of relative advance of EOG

\begin{tabular}{|c|c|c|c|}
\hline \multicolumn{2}{|c|}{$\begin{array}{l}\text { Mean time of relative } \\
\text { advance }( \pm \text { s.D. }) \\
(\text { msec })\end{array}$} & \multicolumn{2}{|c|}{$\begin{array}{l}\text { Mean time of relative } \\
\text { advance in each group } \\
( \pm \text { s.D. })(\mathrm{msec})\end{array}$} \\
\hline Leftward & Rightward & Leftward & Rightward \\
\hline $15.1 \pm 11.5$ & $8.1 \pm 5.3$ & $5.7 \pm 14.4$ & \\
\hline \multirow[t]{2}{*}{$14.5 \pm 7.5$} & $29.4 \pm 25.2$ & & $18.8 \pm 29.1 \ddagger$ \\
\hline & $\mathrm{A}<\mathrm{B}_{\ddagger}^{\dagger}$ & & \\
\hline
\end{tabular}

of a slowly moving visual target depends more on the right hemispheric function in normal subjects. The finding that many of the schizophrenic subjects showed a relative advance of the EOG to the target in the rightward pursuit suggests the dominance of the left hemispheric function in the eye-tracking tasks in schizophrenic subjects.

There have been several reports in the literature which suggest the dominance or overactivation of the left hemisphere in some of schizophrenic patients. Gur (1978) and Schweitzer et al. (1978) found that right handed schizophrenics showed more frequent rightward horizontal eye movements than normals in the study of initial lateral eye movements, even when schizophrenics were given nonverbalspatial stimuli that would activate the right hemisphere. Based on these findings they assumed the presence of the left hemispheric overactivation or dysfunction in schizophrenics. The findings in the present study would also support the hypothesis of the left hemispheric overactivation in the schizophrenic patient.

\section{References}

1) Gur R.E. (1978) Left hemisphere dysfunction and left hemisphere overactivation in schizophrenia. J. abnorm. Psychol., 87, 226-238.

2) Holzman P.S., Proctor L.R. \& Hughes D.W. (1973) Eye tracking patterns in schizophrenia. Science, 181, 179-181.

3) Matsue Y. \& Okuma T. (1981) Flickering light spot as a tracking target for the study of smooth pursuit eye movements in schizophrenics-A new method-. Fol. psychiat. neurol. jap., 35, 437-446.

4) Matsue Y., Wagatsuma S., Ito K. \& Okuma T. (1981) Smooth pursuit eye movements in epileptics under antiepileptic medication. Tohoku J. exp. Med., 134, 341-349.

5) Schweitzer L., Becker E. \& Welsh H. (1978) Abnormalities of cerebral lateralization in schizophrenia patients. Arch. gen. Psychiat., 35, 982-985. 